\title{
Bilateral Cardiac Myxomas and Peripheral Myxomas in a Patient With Recent Myocardial Infarction
}

AGGIE H. M. BALK, MD

SJOERD S. WAGENAAR, MD

ALBERT V. G. BRUSCHKE, MD

Utrecht, The Netherlands
From the Departments of Cardiology and Pathology, St. Antonius Hospital, Utrecht, The Netherlands. Manuscript received January 23, 1979; revised manuscript received and accepted April 11, 1979.

Address for reprints: Albert V. G. Bruschke, MD, Department of Cardiology, St. Antonius Hospital, Jan van Scorelstraat 2, 3583 CP Utrecht, The Netherlands.
Coronary arteriography, performed for recent anterior wall myocardial intarction in a 29 year old man, showed multiple aneurysms of the distal branches of the left coronary artery without evidence of obstructions in the major branches, and two clusters of abnormal vessels, supplying tumors in the right ventricle and the left atrium. At operation and histologic examination both tumors appeared to be myxomas. In addition, two myxomas, located elsewhere in the body, could be proven histologically.

Accounting for more than half of all cases, myxoma is the most frequent primary cardiac tumor. About 75 percent of myxomas originate in the left atrium; they are located less frequently in the right atrium, and rarely in the ventricles. ${ }^{1-15}$ Ten cases of bilateral myxomas have been reported. 16,17

Clinical manifestations of myxoma cordis encompass a variety of symptoms, resulting from valve obstruction, embolization and systemic illness. With current techniques it is nearly always possible to establish the diagnosis. However, because of unusual symptoms, the possibility of myxoma is occasionally overlooked. Recently we encountered a patient who presented with myocardial infarction and bilateral cardiac myxomas in combination with two myxomas located elsewhere in the body.

\section{Case Report}

A 29 year old man was referred to our department for coronary arteriography after a myocardial infarction sustained 3 months previously.

Past medical history: Parinaud syndrome (paralysis of upward gaze with abolition of movements of convergence and pupillary light reflexes) was noted in 1974. In the same year a myxoma of the subcutis of the right shoulder was excised. In 1975 a Hürthle cell adenoma of the thyroid gland was removed. Between 1974 and 1978 the patient had intermittent pains in both legs accompanied by tender red spots on the legs. He had been free of cardiac symptoms until his acute myocardial infarction.

Clinical features: At the time of admission to our department, several months after the myocardial infarction, the patient had no angina pectoris. On physical examination, blood pressure was $130 / 80 \mathrm{~mm} \mathrm{Hg}$. Heart sounds were normal and there were no heart murmurs and no bruits over the peripheral arteries. On the inner surface of the left thigh there was a pedunculated tumor. Some hyperreflexia of the right side of the body was noted.

The electrocardiogram showed inferior, anterior and lateral wall infarction with $\mathrm{S}$ - $\mathrm{T}$ segment elevations in the precordial leads. A chest X-ray film showed a slightly enlarged cardiac silhouette. The pulmonary vasculature was normal.

Laboratory examinations showed normal values for erythrocyte sedimentation rate, blond urea nitrogen, serum creatinine, hemoglobin, transaminases and serum proteins. 
Coronary arteriography and left ventricular angiography: An abnormal large atrial branch of the left circumflex artery divided into a cluster of small vessels (Fig. 1). Flow of contrast medium from the cluster to the left atrial cavity was observed. A branch of the proximal right coronary artery coursing to the same left atrial area showed similar characteristics. Two branches of the right coronary artery terminated as clusters of small vessels in the region of the right ventricle (Fig. 2, top). The terminal branches of the left anterior descending and circumflex arteries showed distally longitudinal narrowings, continuing as aneurysmal dilatations (Fig. 2, bottom). Apart from these changes the coronary arteries were normal.

Lefl ventricular angiography revealed akinesia of the apex and a large portion of the anterior wall. Because the angiographic pattern suggested intracardiac tumor growth, we performed echocardiography and supplementary angiographic studies.

Echocardiography: A mass in the left atrium appeared, in diastole, as multiple abnormal echoes behind the anterior mitral valve leaflet. A second mass, located in the right ventricle, moved into the right ventricular outflow tract in systole.

Angiography of the left atrium showed a filling defect caused by a large lobulated tumor. Right atrial injections revealed a round smooth-walled mobile tumor in the right ventricular outflow tract. Pressure recordings showed no gradients across the mitral valve and the right ventricular outflow tract.

Scintigraphy of the lungs with technetium-99m revealed no abnormalitics. Revicwing the carotid angiogram of 1974 we could detect no obstructions or aneurysms of the cerebral vessels.

Surgical findings: The left ventricle was moderately enlarged. Fibrous scar tissue extended from the apex to anterior and lateral walls. With use of extracorporeal circulation the heart was entered through both the left and the right atria. In the right ventricular outflow tract there was a grey-red glistening tumor attached to the anterior wall by a small pedicle. Extirpation of the tumor necessitated incision through the entire ventricular wall. Two large arteries supplying the tumor

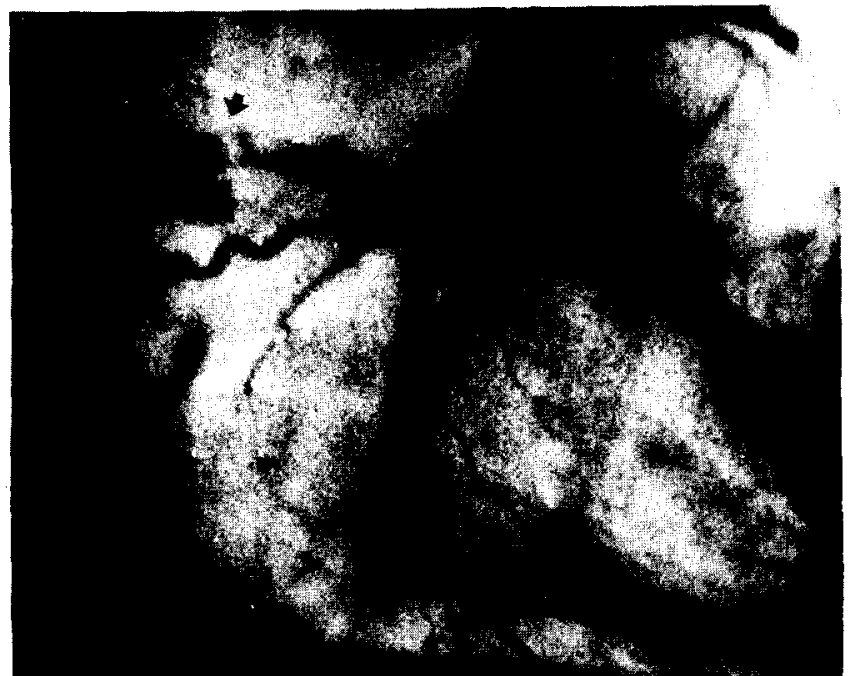

FIGURE 1. Left circumflex coronary arteriogram in right anterior oblique vlew. A large atrlal branch divides into a cluster of small vessels (arrow). were ligated. The left atrial tumor was more friable and was attached over a large area to the interatrial septum. A portion of the atrial septum was excised to remove this tumor. The defect was closed with a Teflon ${ }^{\circledR}$ patch.

Pathologic findings: The tumors of the right ventricle (Fig. 3, top) and left atrium (Fig. 3, bottom) measured 48 by 50 by $28 \mathrm{~mm}$ and 42 by 27 by $24 \mathrm{~mm}$, respectively. The surface of the first tumor was smooth, in contrast to that of the second one, which was irregular and partly villous. Both tumors showed the characteristic histologic findings of myxoma (Fig.
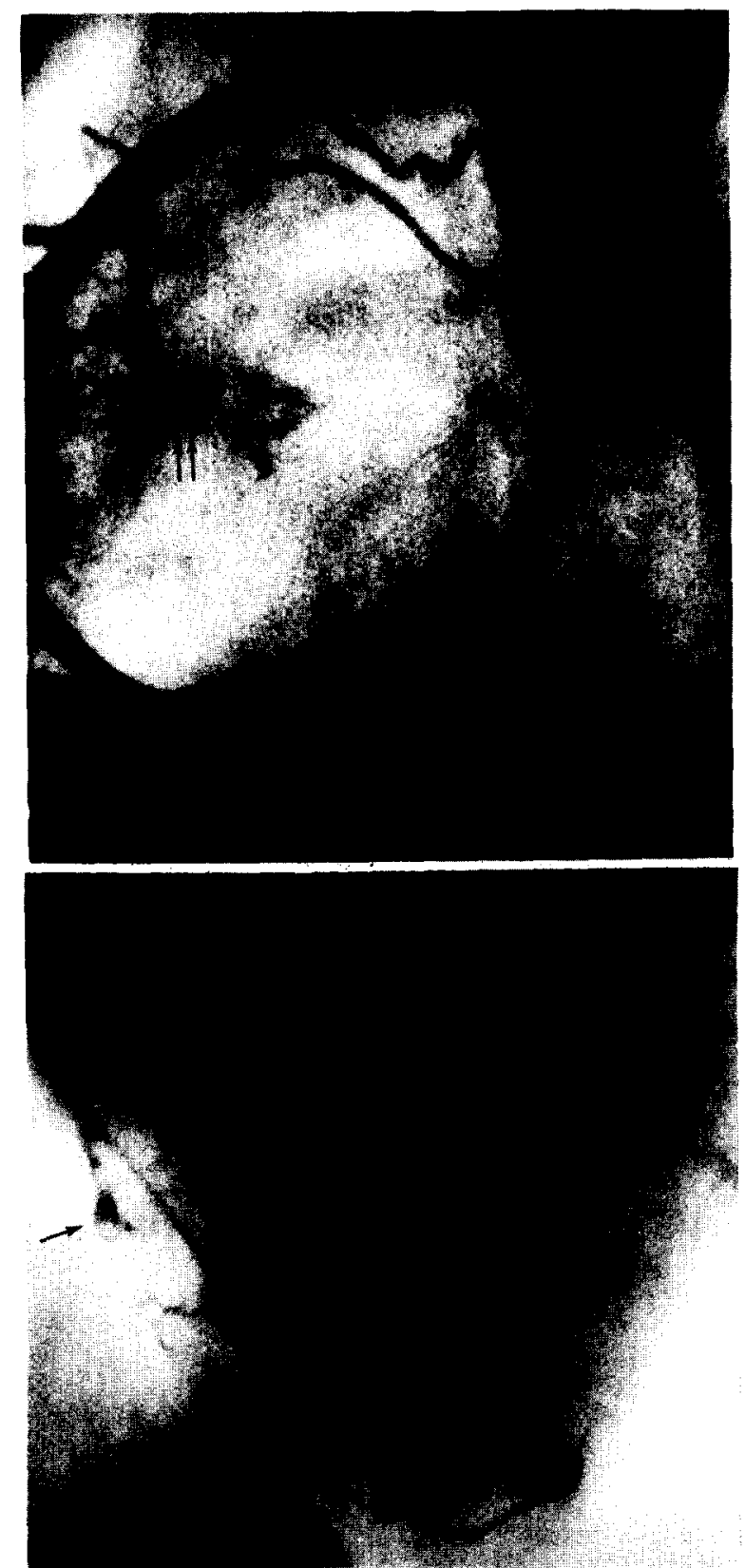

FIGURE 2. Top, right coronary arteriogram in left anterior oblique view. Note two abnormal clusters of vessels, the first originating from right ventricular branches (wide arrow), the second originating from left atrial branches (two thin arrows). Bottom, left coronary arteriogram in craniocaudal right anterior oblique view. Distal branches of both the left anterior descending and circumflex arteries show narrowings and aneurysmal dilatations (arrows) 
4 , top). In the base of the right ventricular myxoma a strikingly large number of vessels was found.

The tumor of the left thigh was extirpated. On histologic examination (Fig. 4, bollom), this also appeared to be a myxoma. No myxomatous tissue could be detected in the walls of the vessels of the subcutis. Vessel wall destruction was not observed. Reviewing the histologic preparations of the tumor removed from the subcutis of the right shoulder in 1974, we confirmed the diagnosis of myxoma.

\section{Discussion}

Sites of multiple tumors: Multichambered cardiac myxomas, usually located in both atria, have been reported several times. The occurrence of myxomas in the left and right ventricles was reported by DeMaria et al. ${ }^{13}$ and in the left atrium and left ventricle by Morgan et al. ${ }^{17}$ However, their occurrence in the left atrium and right ventricle has not previously been reported. The diagnosis of intracardiac tumor growth in our patient was made by demonstration on coronary arteriography of abnormal vessels supplying the tumor. This finding has rarely been described, ${ }^{18-20}$ although myxomas are generally well vascularized.

There is no report, so far as we know, of a combination of intracardiac myxomas and myxomas located elsewhere in the body. We can only speculate as to a causal
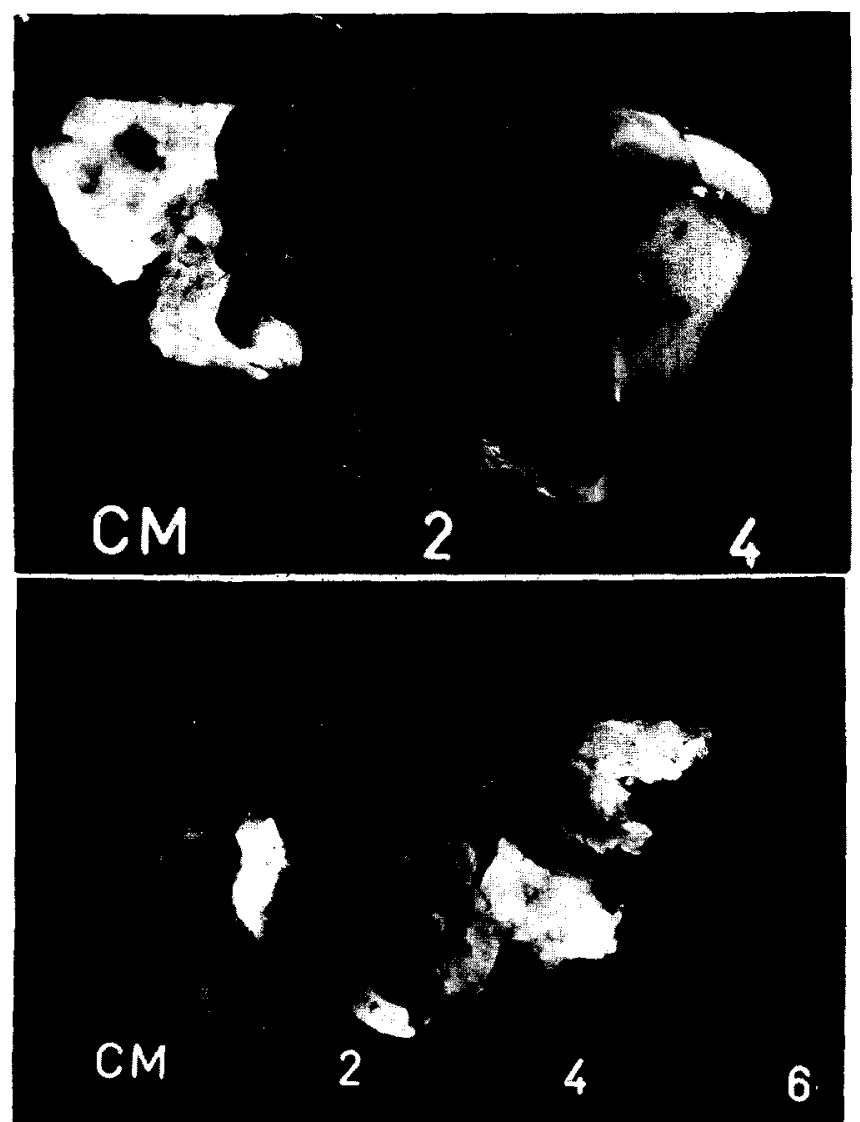

FIGURE 3. Top, myxoma of the right ventricle with a smooth surface. Bottom, myxoma of the left atrium with an irregular and partly villous aspect. relation between the different sites. Price et al. ${ }^{21}$ suggested the possibility of metastatic growth of myxomatous emboli. In our case we found no histologic evidence of a metastatic origin of the myxomas of the left thigh and right shoulder, but such a process cannot be entirely excluded.

Embolic complications: Frequently the first symptoms of myxoma originate from embolic complications. In two large series of postmortem cases reported by Mahaim ${ }^{22}$ and Prichard, ${ }^{23}$ embolization to peripheral arteries, lungs, kidneys and brain was relatively frequent. On a recent review of reported cases, ${ }^{24}$ embolization was demonstrated in 45 to 60 percent of left-sided and in 8 to 10 percent of right-sided cardiac myxomas.

Electrocardiographic evidence of myocardial infarction, present in our patient, has frequently been noted in patients with cardiac myxoma. Myocardial infarction during surgical removal of a left atrial myxoma was noted and reported by Differding et al. ${ }^{25}$ Chamberlin et al, ${ }^{26}$ removed a tumor embolus from the left anterior descending artery during surgery for a left atrial myxoma. With these exceptions only postmortem evidence of coronary embolization from cardiac myxoma has been reported..$^{21,27,29}$ Price et al. ${ }^{21}$ documented

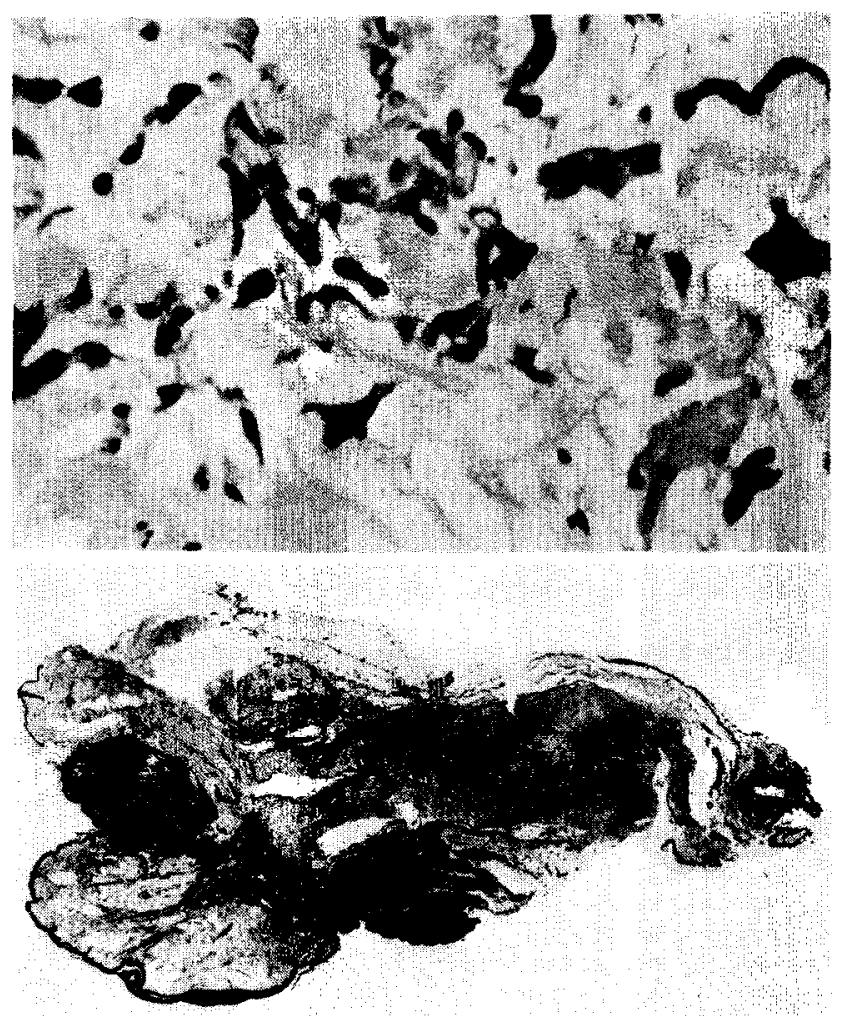

FIGURE 4. Top, microscopic appearance of the myxoma of the right ventricle. (Hematoxylin-eosin, $\times 350$, reduced by 31 percent.) Bottom, light microscopic appearance of the dermal tumor of the left thigh with the characteristic structures of a myxoma. (Alcian Blue $\times 4$, reduced by 31 percent.) 
in one case that myxomatous emboli had partially destroyed the coronary as well as the cerebral arterial walls, resulting in aneurysmal dilatations.

We assume that the patient's neurologic symptoms preceding the myocardial infarction were caused by embolization to the cerebral vessels, although this could not be substantiated with carotid angiography. Similarly, we assume that the intermittent pains in the limbs were caused by ischemia due to embolization.

Angiographic findings: In our patient coronary arterial narrowings and aneurysmal dilatations were demonstrated at angiography. Similar abnormalities, proven to result from tumor emboli, have been observed in the cerebral vessels. ${ }^{17,26,27,30-32}$ Leonhardt and Kullenberg ${ }^{33}$ reported a case of bilateral atrial myxomas with multiple arterial aneurysms, located in the pulmonary, renal and cerebral arteries. We assume that in our case the arteriographic findings of the distal coronary branches were due to myxomatous emboli. 'This explains the occurrence of myocardial infarction in the absence of obstructive lesions in the larger coronary arterial branches. Ours is the first report to describe these unique angiographic findings.

Clinical implications: The occurrence of multiple tumor sites highlights the need to investigate further the metastatic behavior of myxomas. Because left-sided cardiac myxoma may produce coronary embolization, myxoma has to be excluded in cases of myocardial infarction without obstructive lesions in the major branches of the coronary arteries.

\section{References}

1. Ports TA, Schllker NB, Strunk BL: Echocardiography of right ventricular tumors. Circulation 56:439-446, 1977

2. Chandraratna PAN, San Pedro MRCP, Elkins RC, Grantham N: Echocardiographic, angiocardiographic, and surgical corelations in right ventricular myxoma simulating valvar pulmonic steñosis. Circulation 55:6 19-626, 1977

3. Nanda MC, Barold SS, Gramiak R, Ong LS, Heinle RA: Echocardiographic features of right ventricular outflow tumor prolapsing into the pulmonary artery. Am J Cardiol 40:272-276, 1977

4. Snyder SN, Smith DC, Lau FYK, Turner AK: Diagnostic features of right ventricular myxoma. Am Heart J 91:240-249, 1976

5. Zager J, Smith JR, Goldsiein S, Franch RH: Tricuspid and pulmonary valve obstruction relieved by removal of a myxoma of the right ventricle. Am J Cardiol 32:101-104, 1973

6. Gottsegen G, Wessely J, Arvay A, Temesvary A: Right ventricular myxoma simulating pulmonic stenosis. Circulation 27:95-97, 1963

7. Doohen DJ, Greer JW, Diorio N, Timmes JJ: Emergency excision of a myxoma of the right ventricle which was obstructing the right ventricular outflow tract. J Thorac Vasc Surg 47:342-348, 1964

8. Sakakibara S, Osawa M, Konno S, Hasjimoto A, Gomi H, Miyamoto AM, Takao A: Myxoma of the right ventricle of the heart. Am Heart J 69:382-391, 1965

9. Hubbard TF, Neil RN: Myxoma of the right ventricle of the heart. Am Heart J 81:548-553, 1971

10. Ernst RW, Siebel EK, Ogle JC, Chaponan CB, Bashour FA: Successful removal through the main pulmonary artery of a tumo arising from the ventricular septum. Ann Surg 156:54-56, 1962

11. Stoane L, Allen JH, Collins HA: Radiologic observations in cerebral embolisation from left heart myxomas. Radiology 87:262-266. 1966

12. Mandel MM, Strimel WH: Ventricular myxoma associated with cerebral embolism. JAMA 214:2154-2156, 1970

13. DeMaria AN, Vismara LA, Miller RR, Neumann A, Mason DT: Unusual echocardiographic manifestations of right and left heart myxomas. J Thorac Cardiovasc Surg 46:220-226, 1963

14. Thomas GI, Edmark KW, Jones TW, Eyer KM: Myxoma of the left ventricle. J Thorac Cardiovasc Surg 46:220-226, 1963

15. Morrow AG, Kahler RL, Reis RL: Primary myxoma of the right ventricle. Am J Med 40:954-960, 1966

16. Gustafson AG, Edler IG, Dahlback OL: Bilateral myxomas diagnosed by echocardiography. Acta Med Scand 201:393-394, 1977
17. Morgan DL, Palazola J, Reed W, Bell HH, Kindred LH, Beauchamp GD: Left heart myxomas. Am J Cardiol 40:611-614, 1977

18. Marsgall W, Steiner R, Wexler L: "Tumor vascularity" in left atrial myxoma demonstrated by selective coronary arteriography. Radiology 93:815-817, 1969

19. Berman ND, McLaughlin PR, Bigelow wG, Morch JE: Angiographic demonstration of blood supply of right atrial myxoma. $\mathrm{Br}$ Heart J 38:764-766, 1976

20. Stroobant R, Piessens J, De Geest H: Arterial blood supply to a left atrial myxoma diagnosed by coronary arteriography. Eur J Cardiol 5, 6:477-480, 1977

21. Price DL, Harris JL, New PFJ, Cantu RC: Cardiac myxoma. Arch Neurol 23:558-567, 1970

22. Mahaim I: Les tumeurs et les polypes du coeur. Paris, Masson et Cie, 1945, p 160 and 205

23. Prichard RW: Tumors of the heart. AMA Arch Pathol 51:98-128, 1951

24. Meller J, Teichholz LE, Pichard AD, Matta R, Litwak R, Herman MV: Left ventricular myxoma. Echocardiographic diagnosis and review of literature. Am J Med 63:816-823, 1977

25. Differding JT, Gardner RE, Roe BB: Intracardiac myxomas with report of two unusual cases and successful removal. Circulation 23:929-941, 1961

26. Chamberlin SW, Carter JR, Richardson RL: Intraoperative coronary artery embolisation from left atrial myxoma. Anesthesiology 47:301-302, 1977

27. Glaeson EO: Primary myxoma of the heart. Cancer $8: 834-844$, 1955

28. New PFJ, Price DL, Carter B: Cerebral angiography in cardiac myxoma. Radiology 96:335-345, 1970

29. Burton C, Johnston J: Multiple cerebral aneurysms and cardiac myxoma. N Engl J Med 282:35-36, 1970

30. Steinmetz EF, Calanchini PP, Aguilar MJ: Left atrial myxoma as a neurological problem: a case report and review. Stroke 4: $451-458,1973$

31. Cogan DG, Wray SH: Vascular occlusions in the eye from cardiac myxomas. Am J Ophthalmol 80:396-403, 1975

32. Tipton BK, Robertson JT, Robertson JH: Embolism to the central ervous system from cardiac myxoma. J Neurosurg 47:937-940, 1977

33. Leonhardt ETG, Kullenberg KPG: Bilateral atrial myxomas with multiple arterial aneurysms - a syndrome mimicking polyarteritis nodosa. Am J Med 62:792-794, 1977 